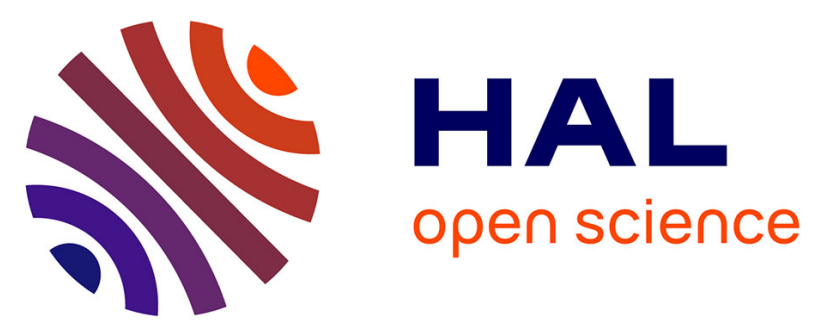

\title{
In vitro biotransformation of surfactants in fish. Part II-Alcohol ethoxylate (C16EO8) and alcohol ethoxylate sulfate (C14EO2S) to estimate bioconcentration potential.
}

\author{
Scott D Dyer, Mary Jo Bernhard, Christina Cowan-Ellsberry, Elisabeth \\ Perdu, Susanne Demmerle, Jean Pierre J. P. Cravedi
}

\section{To cite this version:}

Scott D Dyer, Mary Jo Bernhard, Christina Cowan-Ellsberry, Elisabeth Perdu, Susanne Demmerle, et al.. In vitro biotransformation of surfactants in fish. Part II-Alcohol ethoxylate (C16EO8) and alcohol ethoxylate sulfate (C14EO2S) to estimate bioconcentration potential.. Chemosphere, 2009, 76

(7), pp.989-98. 10.1016/j.chemosphere.2009.04.011 . hal-02659735

\section{HAL Id: hal-02659735 \\ https://hal.inrae.fr/hal-02659735}

Submitted on 30 May 2020

HAL is a multi-disciplinary open access archive for the deposit and dissemination of scientific research documents, whether they are published or not. The documents may come from teaching and research institutions in France or abroad, or from public or private research centers.
L'archive ouverte pluridisciplinaire HAL, est destinée au dépôt et à la diffusion de documents scientifiques de niveau recherche, publiés ou non, émanant des établissements d'enseignement et de recherche français ou étrangers, des laboratoires publics ou privés. 


\title{
In vitro biotransformation of surfactants in fish. Part II - Alcohol ethoxylate (C16EO8) and alcohol ethoxylate sulfate (C14EO2S) to estimate bioconcentration potential
}

\author{
Scott D. Dyer ${ }^{\mathrm{a}, *}$, Mary Jo Bernhard ${ }^{\mathrm{a}}$, Christina Cowan-Ellsberry ${ }^{\mathrm{a}}$, Elisabeth Perdu-Durand ${ }^{\mathrm{b}}$, \\ Susanne Demmerle ${ }^{\mathrm{b}}$, Jean-Pierre Cravedi ${ }^{\mathrm{b}}$ \\ ${ }^{a}$ The Procter and Gamble Company, Central Product Safety Division, Miami Valley Innovation Center, 11810 E. Miami River Road, P.O. Box 538707, \\ Cincinnati, OH 45253-8707, USA \\ b INRA, Institut National de Recherche Agronomique, UMR1089 Xénobiotiques, BP 93173, F31300 Toulouse, France
}

\section{A R T I C L E I N F O}

\section{Article history:}

Received 12 November 2008

Received in revised form 27 March 2009

Accepted 3 April 2009

Available online 9 May 2009

\section{Keywords:}

Surfactant

Fish

Hepatocyte

Metabolism

Toxicology

\begin{abstract}
A B S T R A C T
Recent regulatory pressures (e.g., REACh, CEPA) requiring bioaccumulation assessments and the need for reduced animal use have increased the necessity for the development of in vitro-based methods to estimate bioaccumulation. Our study explored the potential use of subcellular and cellular hepatic systems to determine the biotransformation potential of two surfactants: octaethylene glycol monohexadecyl ether (C16EO8) and diethylene glycol monotetradecyl ether sulfate (C14EO2S). The subcellular systems tested were liver homogenates and microsomes from the common carp (Cyprinus carpio) and rainbow trout (Oncorhynchus mykiss). Cellular systems consisted of primary hepatocytes from the common carp (C. carpio) and PLHC-1 cells, hepatocarcinoma cells from the desert topminnow (Poeciliopsis lucida) cell line. Each in vitro system was exposed to radiolabeled test compounds and assayed for biotransformation using liquid scintillation and thin layer chromatographic methods. First-order kinetics were used to estimate rates of biotransformation. Bioconcentration of test materials in fish were predicted using an in vitro to in vivo metabolic rate extrapolation model linked to a mass-balance model commonly used to predict bioaccumulation in fish. Both subcellular and cellular tests using microsomes, liver homogenates and hepatocytes respectively showed biotransformation of the parent surfactants. Biotransformation rates were fastest for hepatocytes, followed by microsomes and homogenates. Rates were too low from homogenate tests to extrapolate to in vivo-based biotransformation rates using the extrapolation model. Trout microsomes metabolized C16EO8 faster than carp microsomes, yet rates were approximately the same for C14EO2S. Predicted BCF values incorporating in vitro biotransformation rates from hepatocytes were similar to measured in vivo or USEPA's bioconcentration model (BCFWIN) predicted values. Predicted BCF values using microsomal-based rates from trout and carp studies were only slightly less than default BCF values which assumes a linear $\log$ Kow to BCF relationship with no biotransformation. However, hepatocyte-based results showed substantially decreased BCFs compared to the default BCF values. These results indicate that BCF estimates based on in vitro metabolic rates can provide reasonable estimates of in vivo BCF values, therefore, supporting the use of in vitro approaches within a tiered approach to assess bioconcentration.
\end{abstract}

(c) 2009 Elsevier Ltd. All rights reserved.

\section{Introduction}

Fish are the primary organisms used to assess the bioconcentration factor (BCF) of chemicals. In vivo experimental determination of the BCF is expensive and time-consuming (e.g., OECD 305E, 1996), making the potential measurement of thousands

\footnotetext{
* Corresponding author. Tel.: +1 5136271163 ; fax: +1 5136271208 .

E-mail address: dyer.sd@pg.com (S.D. Dyer).
}

of chemicals via new chemical management procedures such as REACh and CEPA (DGEE, 2003; Government of Canada, 1999) impractical. Additionally, an ethical goal of animal welfare includes the reduction of fish sacrificed during testing, in accordance with societal desires. Within this context, there is a need for biologically-based estimation methods for BCF that can supply the missing data and reduce the numbers of fish tested (Meylan et al., 1999). It is well established that the bioconcentration of a chemical is related to its lipophilicity (Veith et al., 1979), hence 
it is possible to predict the BCF for certain classes of organic chemicals from their octanol/water partition coefficient (Kow; Connell, 1993; Neff, 2002). Even so, some organic chemicals do not fit with this model as some are metabolized relatively rapidly by fish and/or are eliminated faster than would be expected if diffusion was the only process involved (Cravedi, 2002). Fish have similar biotransformation enzymes as those found in mammals, including those catalyzing phase I and phase II reactions, although reactivity is often lower (Cravedi 2002; Han et al., 2007). Meylan et al. (1999) empirically incorporated metabolism into a general estimation model for BCF by defining correction factors for those chemical classes for which it is known to have a significant influence. However, published studies on in vivo or in vitro fish metabolism are scarce for a large number of chemical classes for which correction factors might be developed. This is especially the situation for surfactants.

Three recent reviews have illustrated the potential for in vitro systems to provide biotransformation rates for the estimation of an in vivo 'B' (bioconcentration and/or bioaccumulation) assessment (DeWolf et al., 2006; Nichols et al., 2006, 2007). Cravedi (2002) and Nichols et al. (2006, 2007) acknowledge that biotransformation rate is a dominant factor in determining the extent to which chemicals may bioconcentrate. For example, (Nichols et al., 2006,2007 ) illustrated that in vitro biotransformation rates from hepatic systems (e.g., microsomes, S9 fractions and hepatocytes) can be used as inputs in a fish bioaccumulation model (Arnot and Gobas, 2004, also see http://www.rem.sfu.ca/toxicology/models/models.htm) that incorporates the use of metabolism. Recent studies by Han et al. (2007, 2009), Cowan-Ellsberry et al. (2008) and Dyer et al. (2008) have shown how in vitro biotransformation rates can be scaled up to in vivo rates, thereby enabling the prediction of BCF values that incorporate metabolism.

Research has shown that measured bioconcentration factors (BCFs) of surfactants in fish are lower than predictions via Kow-based models due to the metabolism and rapid depuration (Tolls et al., 1994, 1995, 1997, 1998, 1999; Newsome et al., 1995). Tolls et al., (2000) demonstrated via in vivo experiments with fish exposed to the alcohol ethoxylate (AE) C16EO8 and other homologs that measured BCFs were less than predicted, based on Kow-only expectations. AEs have been shown to be extensively metabolized by mammals. For example Drotman (1980) found that rats orally dosed with AEs (e.g., C12EO6, C13EO6) were rapidly eliminated in urine, presumably as polar metabolites. According to Newsome et al. (1995) and Tolls and Sijm (1999), AEs may be biotransformed via a couple of pathways, such as: initial $\omega$-oxidation of the alkyl-terminus and/or ether cleavage leading to a short chain polyethoxylate glycol and a carboxylic acid followed by $\beta$-oxidation. AEs have also been shown to be biotransformed in wastewater via ether cleavage (Matthijs et al., 1995).

Since determining biotransformation in vitro in fish is a relatively new field, our study investigated the potential use of several in vitro systems to assess in vivo biotransformation and bioconcentration in fish by exposing hepatic cells and subcellular fractions to $\mathrm{C} 16 \mathrm{EO} 8$ and $\mathrm{C} 14 \mathrm{EO} 2 \mathrm{~S}$. Furthermore, these in vitro biotransformation kinetics were extrapolated up to in vivo responses (kinetics, BCF) to demonstrate the validity of the in vitro approach.

In the cell systems, we determined cytotoxicity, uptake and biotransformation in two in vitro cellular systems: fresh isolated primary hepatocytes from the common carp (Cyprinus carpio) and an immortalized cell line (PLHC-1). In subcellular systems, we determined biotransformation rates in liver homogenates and microsomal fractions collected from rainbow trout (Oncorhynchus mykiss) and the common carp. This study (as well as Dyer et al., 2008) was conducted under an umbrella of surfactant-based re- search sponsored by ERASM (Environmental Risk Assessment and Management, see http://www.erasm.org/study.htm) with the purpose of developing in vitro methods for bioaccumulation.

\section{Methods}

\subsection{Test chemicals and characterization}

\subsubsection{Octaethylene glycol monohexadecyl ether (C16EO8)}

Octaethylene glycol monohexadecyl ether was obtained from Fluka Chemical Corp (Milwaukee, WI; catalogue \#74717). An assay by GC area listed on manufacturer's certificate of analysis stated $100 \%$ purity. An in-house characterization by super fluid critical mass spectroscopy (SFC/MS) indicated $92.1 \%$ purity. Additional in-house characterization by NMR indicated an average chain length of C16EO8.5.

Radiolabeled C16EO8 $\left({ }^{14} \mathrm{C}-\mathrm{C} 16 \mathrm{EO} 8\right)$ was synthesized by Procter and Gamble Company (P\&G, Cincinnati, Ohio) synthesis laboratory in 2003. The label was located on the alkyl chain alpha to the ethoxylate. The specific activity was $1030.45 \mathrm{MBq} / \mathrm{g}$. Thin layer chromatography using radioactivity detection (TLC-RAD) using two different solvent systems showed a single peak. Proton NMR indicated a spectrum consistent with the structure.

\subsubsection{Diethylene glycol monotetradecyl ether sulfate (C14EO2S)}

Non-radiolabeled C14EO2S (purity 94.7\%) and ${ }^{14} \mathrm{C}-\mathrm{C} 14 \mathrm{EO} 2 \mathrm{~S}$ (specific activity $1073.3 \mathrm{MBq} / \mathrm{g}$ were synthesized by the Procter and Gamble Company (P\&G), Cincinnati, Ohio. The radiolabel was located on the alkyl chain alpha to the ethoxylate and normal phase TLC-RAD indicated a single peak.

7-Ethoxy[3- $\left.{ }^{14} \mathrm{C}\right]$-coumarin $(2038.7 \mathrm{MBq} / \mathrm{mmol}$, radiochemical purity $>98 \%$ ), used to measure cytochrome P450 activity, was from Amersham (Les Ulis, France). Unlabeled ethoxycoumarin was from Sigma (Saint Quentin Fallavier, France).

\subsection{Fish culture}

\subsubsection{Culture I}

C. carpio used by P\&G were obtained through Aquatic Research Organisms (ARO, Hampton, NH, USA) and were fed Hikari Koi Staple Diet (Hayward, California, USA) twice daily. Fish were acclimated for a minimum of $8 \mathrm{~d}$ before use and were not fed approximately $18 \mathrm{~h}$ prior to test initiation. Cultures were maintained in large (890 L) flow-through aquaria supplied with blended well water (hardness $\sim 180 \mathrm{mg} \mathrm{CaCO} / \mathrm{L} ; \mathrm{pH} \sim 8$; and temperature $22-26^{\circ} \mathrm{C}$ ). Aquaria water was aerated and filtered through canister filters containing carbon and zeolite. A $16 \mathrm{~h}$ light: $8 \mathrm{~h}$ dark cycle at light intensities ranging from 50 to 90 LUX was provided. Fish wet weights ranged from 156.6 to $385.5 \mathrm{~g}$ at the time of sacrifice. Liver and gonads were then immediately removed and weighed.

\subsubsection{Culture II}

Carp (C. carpio) weighing approximately $250 \mathrm{~g}$ were obtained from "Station Experimentale Piscicole de l'Indre" (SEPIB, Le Blanc, France) and were fed a carp intensive diet (SARB, Tours, France) twice daily. The constant water conditions were kept: water temperature $\left(24 \pm 2{ }^{\circ} \mathrm{C}\right)$, hardness $\left(150-220 \mathrm{mg} \quad \mathrm{CaCO}_{3} / \mathrm{L}\right)$ and $\mathrm{pH} \sim 7.2$.

\subsubsection{Culture III}

Rainbow trout ( $O$. mykiss) having a mean weight of approximately $220 \mathrm{~g}$ were from INRA pisciculture at Donzacq, France, and were fed once a day a pelleted commercial feed (Trouvit, Fontaine Les Vervins, France). The trout culture conditions were: water temperature $\left(17 \pm 1^{\circ} \mathrm{C}\right)$, hardness $(\sim 120 \mathrm{mg} \mathrm{CaCO} / \mathrm{L})$ and an average $\mathrm{pH}$ of 7.4 . 


\subsection{Cellular and subcellular preparation and characterization}

\subsubsection{Isolated primary hepatocyte preparation (from Culture I)} Hepatocyte preparation followed the protocol described by Dyer et al. (2008). Briefly, hepatocytes were isolated via a two step process involving an initial digestion with $1 \mathrm{M}$ collagenase (Type 1 , Sigma Aldrich, St. Louis, MO, USA) and $2 \mathrm{M}$ calcium chloride in a trypsinizing flask at room temp $\left(\sim 20^{\circ} \mathrm{C}\right)$ for 20 min using a stir plate, followed by a $1-2 \mathrm{~h}$ trypsinization step ( $0.05 \%$ trypsin and $0.53 \mathrm{mM}$ ethylenediaminetetraacetic acid (EDTA) per $3 \mathrm{~g}$ of tissue). Cells in the supernatant were transferred into Leibovitz -15 (L-15, Gibco $^{\circledR}$, Invitrogen Corp., Carlsbad, CA, USA) media supplemented with $5 \%$ FBS (fetal bovine serum) and gentamicin sulfate. This final step halts the trypsin-based reaction. Cells in media were centrifuged at $100 \mathrm{~g}$ for $7 \mathrm{~min}$. The resulting pellet was remixed with $10-15 \mathrm{~mL}$ of L-15 media and then filtered through a nylon filter $(250 \mu \mathrm{m}$, Sefar Filtration, Inc., Kansas City, MO, USA). Mean and standard deviation of cellular yields were $8.4 \times 10^{7}$ and $2.1 \times 10^{7}$ cells/g liver, respectively. Approximately 400000 primary cells (determined via direct counting using a hemacytometer) were seeded per well in 96-well microtiter plates. Primaria ${ }^{\mathrm{TM}}$ plates (BD Biosciences, Rockville, MD, USA) were used for primary cells to obtain sufficient attachment.

\subsubsection{Culture of PLHC-1 cells}

The immortalized cell line, PLHC-1, was derived from a hepatocellular carcinoma induced in Poeciliopsis lucida, a desert topminnow, using 7,12-dimethyl-benz(a)anthracene (Schultz and Schultz, 1985). Cells were originally obtained from Dr. L. Hightower, Univ. Connecticut, Storrs, CT, USA and cryogenically preserved in liquid nitrogen. Cells were cultured in Leibovitz-15 media, supplemented 5\% FBS $\left(\mathrm{Gibco}^{\circledR}\right)$ and gentamicin sulfate. Cultures were used within 20 passages of being removed from cryogenic storage. Cells were grown to confluency in T-75 flasks and then subcultured by dissociating with $0.05 \%(\mathrm{w} / \mathrm{v}$ ) trypsin and $0.5 \mathrm{mM}$ EDTA in calcium and magnesium free phosphate buffered saline. Approximately 100000 PLHC-1 cells (determined via direct counting using a hemacytometer) seeded per well in 96-well microtiter plates.

\subsubsection{Subcellular system preparations (from Cultures II and III)}

Carp livers were weighed and divided into three pools of 15 livers each. Trout livers were collected from nine fish and pooled in three groups of three samples each. Thawed livers were sliced into small pieces then washed twice with cold homogenizing buffer consisting of $25 \mathrm{mM}$ HEPES, $1.25 \mathrm{mM}$ EDTA, $1 \mathrm{mM}$ DTT and $10 \%$ glycerol adjusted to $\mathrm{pH} 7.4$. Liver fragments were then homogenized mechanically using a Potter homogenizer as described by Perdu-Durand and Cravedi (1989). The suspension was filtered through two cotton meshes that were laid upon another and then adjusted to $4 \mathrm{~mL}$ buffer per gram of liver. The first centrifugation was performed at $600 \mathrm{~g}$ for $10 \mathrm{~min}$. Supernatants were carefully removed and $1 \mathrm{~mL}$ aliquots of homogenate suspension were frozen in appropriate vials and stored at $-80^{\circ} \mathrm{C}$. The remaining supernatant was transferred into ultracentrifuge tubes for a second centrifugation at $10000 \mathrm{~g}$ (ultracentrifuge model Centrikon T-1045 - Kontron Instruments, Zürich, Switzerland) for $20 \mathrm{~min}$. For microsomal fractions, the supernatant obtained was transferred again into ultracentrifuge tubes and spun at $105000 \mathrm{~g}$ for $60 \mathrm{~min}$. The resulting pellets were then resuspended and homogenized mechanically with Potter homogenizer in a buffer $\mathrm{PO}_{4} \mathrm{Na} / \mathrm{K} 50 \mathrm{mM}$, pH 7.4 containing $1 \mathrm{mM}$ EDTA, $1 \mathrm{mM}$ DTT and 20\% glycerol. The microsomal suspension was brought to a total volume of $1 \mathrm{~mL}$ buffer per gram of liver. Aliquots of microsomes $(0.5 \mathrm{~mL})$ were frozen and stored at $-80^{\circ} \mathrm{C}$.

\subsubsection{Characterization of the subcellular fractions}

Subcellular fractions were characterized for total protein, esterase and ECOD (Ethoxycoumarin O-Deethylase) activities. Total protein was determined via the Lowry method, using bovine serum albumin as a standard and was measured by the reaction with Folin's phenol reagent for each of the pooled samples (homogenate, microsomes). Measurements were performed on an UV spectrophotometer set at $750 \mathrm{~nm}$ (Uvikon 810 - Kontron Instruments, Zürich, Switzerland). Samples were analyzed in triplicate and compared to the standard curve with bovine serum albumin concentration ranging from $0.02-0.20 \mathrm{mg} / \mathrm{mL}$. Protein concentration was expressed in $\mathrm{mg} / \mathrm{mL}$. Esterase activity was assayed by measuring at $405 \mathrm{~nm}$ the production of p-nitrophenol from p-nitrophenyl acetate. The protein subcellular fraction $(0.02 \mathrm{mg})$ was added to $3 \mathrm{~mL}$ medium containing $20 \mathrm{mM}$ phosphate buffer $\mathrm{pH}$ 7.4, $1 \mathrm{mM}$ EDTA and $0.1 \%$ Triton X100. The reaction was performed at $25^{\circ} \mathrm{C}$ and was started by addition of $10 \mu \mathrm{L}$ of $0.1 \mathrm{M}$ p-nitrophenol acetate in ice-cold methanol and followed up for $3 \mathrm{~min}$. A blank (without enzyme) was run simultaneous in order to permit correction for spontaneous substrate hydrolysis. A calibration curve was used to calculate the quantity of p-nitrophenol formed. Samples were measured in triplicate and esterase activity was expressed in $\mu \mathrm{mol}$ p-nitrophenol formed $/ \mathrm{h} / \mathrm{mg}$ protein. ECOD activity was determined using ${ }^{14} \mathrm{C}$-labeled 7 -ethoxycoumarin as the substrate (10 nmol, $9167 \mathrm{~Bq}$ ) and incubated in $1 \mathrm{~mL}$ PO4 Na/K $0.1 \mathrm{M}, 5 \mathrm{mM}$ $\mathrm{MgCl} 2$ buffer ( $\mathrm{pH} 7.4$ ) containing the subcellular fraction (10 mg protein homogenate, or $2 \mathrm{mg}$ protein microsomes) and a NADPHgenerating system (NADP $1.27 \mathrm{mM}$, glucose 6-phosphate $5 \mathrm{mM}$ and glucose 6-phosphate dehydrogenase $2 \mathrm{IU}$ ).

After $2 \mathrm{~h}$ incubations at $25^{\circ} \mathrm{C}, 3 \mathrm{~mL}$ methanol was added to stop the reaction process and samples were stored at $4{ }^{\circ} \mathrm{C}$ until HPLC analysis. Post incubation, samples were centrifuged, protein precipitated and then evaporated and analyzed by HPLC as described by Zalko et al. (1998). The analyses were performed on a C-18 reversed-phase column (ODS2 Spherisorb, $4.6 \times 250 \mathrm{~mm}$; $5 \mu \mathrm{m}$; Interchrom, Montluçon, France) using a Spectra Physics P1000 system (Les Ulis, France). The flow rate was $1 \mathrm{~mL} / \mathrm{min}$ and the temperature was controlled at $30^{\circ} \mathrm{C}$. Mobile phases consisted of ammonium acetate buffer ( $50 \mathrm{mM}, \mathrm{pH} 5)$ and acetonitrile $85: 15$ $(\mathrm{v} / \mathrm{v})$ for $\mathrm{A}$ and ammonium acetate buffer $(50 \mathrm{mM}, \mathrm{pH} 5)$ and acetonitrile 20:80 (v/v) for B. A two-step gradient was developed as follows: $0-5 \mathrm{~min}, 100 \% \mathrm{~A}$; 5-25 min, linear gradient from $100 \% \mathrm{~A}$ to $50: 50(\mathrm{v} / \mathrm{v}) \mathrm{A} / \mathrm{B}$; linear gradient leading to $100 \% \mathrm{~B}$. The eluent was monitored by ${ }^{14} \mathrm{C}$ detection with a Packard Flo-One A500 (Packard Instrument Co, Downers Grove, IL), using Flo-Scint II as liquid scintillation cocktail (Perkin Elmer Life and Analytical Sciences, Shelton, CT, USA). The chromatographic conditions permitted the separation and the quantification of 7-ethoxycoumarin and its major metabolite, 7-hydroxycoumarin. ECOD activity was expressed as pmol hydroxycoumarin formed $/ \mathrm{h} / \mathrm{mg}$ protein. The effect of surfactant concentrations on ECOD activity were investigated by exposing carp homogenate and microsomes to 10 and $100 \mu \mathrm{M}$ of $\mathrm{C} 16 \mathrm{EO} 8$ and $\mathrm{C} 14 \mathrm{EO} 2 \mathrm{~S}$.

\subsection{Cytotoxicity assays}

Cytotoxicity tests were conducted to determine the maximum concentration suitable for cellular biotransformation assays (i.e., sans-toxicity, $\leqslant \mathrm{EC}_{0}$ ). Cytotoxicity for $\mathrm{C} 16 \mathrm{EO} 8$ and $\mathrm{C} 14 \mathrm{EO} 2 \mathrm{~S}$ was determined via uptake of neutral red (NRU) dye into lysosomes. Concentration-responses were expressed as percent control compared to micromolar $(\mu \mathrm{M})$ surfactant concentration. Neutral red uptake serves as an indicator of living cells.

Ninety-six well microtiter plates were seeded with PLHC- 1 or primary cells $24 \mathrm{~h}$ prior to test initiation and incubated with supplemented L-15 media at $30^{\circ} \mathrm{C}$. After $24 \mathrm{~h}$, media was removed 
from the plate wells and replaced with $200 \mu \mathrm{L}$ of dosing dilutions containing the test substance prepared in supplemented L-15 media. Nine dosing solutions were developed for C16EO8 ranging from 10 to $90 \mu \mathrm{M}$ for primary cells and 2 to $34 \mu \mathrm{M}$ for PLHC- 1 cells. Nine dosing solutions for C14EO2S ranged from 50 to $250 \mu \mathrm{M}$ for both cell types.

Cells were incubated with test chemicals for approximately 24 $( \pm 3)$ h. Test solutions were subsequently removed and replaced with $200 \mu \mathrm{L}$ media containing neutral red $(40 \mu \mathrm{g} / \mathrm{mL})$ and were incubated at $30^{\circ} \mathrm{C}$ for $2-3 \mathrm{~h}$. Cells were then fixed with $100 \mu \mathrm{L}$ of $10 \%$ formalin $/ 10 \%$ calcium chloride for approximately $3 \mathrm{~min}$ and then media removed. After air drying, $100 \mu \mathrm{L}$ of extraction solution (50\% ethanol and $1 \%$ acetic acid in water) was added to microplates, mixed for $10 \mathrm{~min}$, then another $100 \mu \mathrm{L}$ added and mixed again for $10 \mathrm{~min}$. Absorbance was read on a spectrophotometer at $540 \mathrm{~nm}$ (baseline subtract at $630 \mathrm{~nm}$ ).

Concentration-responses were determined by Table Curve 2D (Systat Software Inc., Richmond, California, USA) using logistic dose response equations. EC50 and 95\% confidence limit values were determined from Table Curve predicted evaluation tables.

\subsection{Biotransformation studies}

\subsubsection{Incubations with hepatocytes}

Incubations for kinetics studies were conducted at concentrations below the ECO as indicated by NRU. Due to a slight increased sensitivity of PLHC-1 cells to C16EO8 compared to primary hepatocytes, kinetics assays were conducted at 2.5 and $5 \mu \mathrm{M}$, respectively. All kinetic assays for AES were conducted at $40 \mu \mathrm{M}$.

Several Primaria ${ }^{\mathrm{TM}}$ microtiter plates were seeded with both primary cells and PLHC-1 at densities of 400000 and 100000 cells per well, respectively, approximately $24 \mathrm{~h}$ prior to dosing with surfactant. Stock solutions were prepared in L-15 media and verified via liquid scintillation counting. Media were removed from seeded microplates and then each test well was dosed with $200 \mu \mathrm{L}$ of dosing solution. Control wells were filled with $200 \mu \mathrm{L}$ of L-15 media only. Additionally, wells without cells (blanks) were dosed for determination of surfactant absorption to plate well surfaces.

Microtiter plates were sacrificed at several time points: 0.5-, 2-, 5-, 10-, 24- and 48-h. Media overlying the cells was placed into vials for total radioactivity counts (LSC) and to determine the proportion of radiolabel biotransformed (via TLC-RAD, thin layer chromatography-radioactivity detection). Cells were subsequently removed from wells via trypsinization ( $30 \mu \mathrm{L}$ of $0.05 \%$ (w/v) tryp$\sin / 0.5 \mathrm{mM}$ EDTA for $1 \mathrm{~min}$, followed by two rinses of either Dulbecco's phosphate buffered saline (DPBS) or de-ionized water) and counted for radioactivity using LSC and TLC-RAD. Samples for radioactivity analysis used water as the final rinse, whereas wells that were enumerated for cell number used DPBS. The "well rinse' of cell blank controls was subtracted from the cell fraction to account for well wall adsorption. Biotransformation in media and cells was halted by immediately freezing collected samples in liquid nitrogen, and then stored at $-80^{\circ} \mathrm{C}$. Triplicate wells were sampled for each time point for the kinetics studies.

\subsubsection{Incubations with subcellular fractions}

Frozen aliquots of carp liver homogenates or microsomes were thawed and kept on ice. ${ }^{14} \mathrm{C}$-Labeled surfactants were incubated in a phosphate buffer $\left(1 \mathrm{~mL} \mathrm{PO}_{4} \mathrm{Na} / \mathrm{K}\right.$ buffer $0.1 \mathrm{M}, 5 \mathrm{mM} \mathrm{MgCl}$, $\mathrm{pH}$ 7.4) with a NADPH-generating system (NADP $1.27 \mathrm{mM}$, glucose 6-phosphate $5 \mathrm{mM}$ and glucose 6-phosphate dehydrogenase $2 \mathrm{IU}$ ) containing the subcellular fractions (homogenate: $10 \mathrm{mg}$ protein, or microsomes: $2 \mathrm{mg}$ protein). Incubations were conducted at $25^{\circ} \mathrm{C}$ for $2 \mathrm{~h}$, while shaking. Various concentrations were tested. Blank controls (inactivated subcellular fraction via immersion in $100{ }^{\circ} \mathrm{C}$ water for $3 \mathrm{~min}$ ) were systematically conducted in parallel with treatments. Biotransformation reactions were halted by adding $3 \mathrm{~mL}$ methanol. Subsequently, samples were placed on ice for $10 \mathrm{~min}$ to precipitate the proteins and then were centrifuged at $8000 \mathrm{rpm}$ for $10 \mathrm{~min}$. The supernatant was transferred into $15 \mathrm{~mL}$ Corex tubes, and submitted to a second centrifugation $(8000 \mathrm{rpm}$, $10 \mathrm{~min}$ ). An aliquot of the supernatant $(500 \mu \mathrm{L}$, corresponding to approximately $500 \mathrm{~Bq}$ ) was evaporated to dryness with a vacuum concentrator Speed Vac SC 110A (Thermo Savant, USA). Dried samples were resuspended in $20 \mu \mathrm{L}$ methanol prior to TLC analysis.

\subsection{Analytical}

\subsubsection{Liquid scintillation counting}

The radioactivity of each incubation medium was determined by direct counting on a scintillation counter (Tricarb 2200CA, Packard Instruments, Meriden, CT, USA), using Ultima Gold (Perkin Elmer Life and Analytical Sciences, Shelton, CT, USA) as the scintillation cocktail.

\subsubsection{Thin layer chromatographic analysis for hepatocytes}

Frozen samples were lyophilized to dryness and then stored at $4{ }^{\circ} \mathrm{C}$ until extracted with chloroform: methanol $(25: 75, \mathrm{v} / \mathrm{v})$. Cell samples, due to their low activity, were extracted with $400 \mu \mathrm{L}$ whereas media samples were extracted with $600 \mu \mathrm{L}$ by vortex mixing and sonication $\left(\sim 20 \mathrm{~min}\right.$ at $\left.40^{\circ} \mathrm{C}\right)$. Aliquots of extraction solvent were counted by LSC to determine extraction efficiency. Another aliquot was used for TLC analysis. For cells, extracts from multiple vials were used for increased activity.

C16EO8 was analyzed using normal phase thin layer chromatography with non-conditioned plates (Whatman, Florham Park, New Jersey, USA, LK5 Silica gel $15 \mathrm{~A}, 250 \mu \mathrm{M}$ ) and an elution solvent of chloroform/methanol/formic acid (90:10:1, v/v/v). The samples of the C14EO2S cell kinetics test were analyzed using normal phase TLC with non-preconditioned silica gel. The elution solvent consisted of chloroform/methanol/formic acid (160:50:2, v/v/ v). All plates were scanned on a Bioscan Imaging Scanner for radioactivity. Chromatograms were manually integrated and the percent of total activity for individual peaks was reported.

\subsubsection{Thin layer chromatographic analysis for subcellular fractions}

Thin Layer Chromatography (TLC) separation of C16EO8 and C14EO2S and corresponding metabolites produced in incubations with subcellular fractions was performed on silica gel pre-coated plates (Kieselgel 60, without fluorescent indicator, $0.25 \mathrm{~mm}$ ) from Merck, Darmstadt, Germany. Radioactive areas were located and quantified by an automatic TLC-Linear Analyzer LB 284/285 (Berthold, Wilbad, Germany) equipped with a Chroma 1D software. Two solvent mixtures were used: chloroform/methanol/formic acid 90:10:1 v/v/v for C16EO8 and chloroform/methanol/water/formic acid $80: 25: 3: 2 \mathrm{v} / \mathrm{v} / \mathrm{v} / \mathrm{v}$ for C14EO2S.

\subsection{Kinetics}

Uptake and loss of parent molecules and generation of metabolites were determined via three different rate equations, each in Table Curve 2D.

$$
\begin{aligned}
& {[\mathrm{A}](t)=[A]_{0} e^{-k_{1} t}} \\
& {[\mathrm{~B}](t)=\frac{k_{1}}{k_{2}-k_{1}}\left(e^{k_{1} t}\right)} \\
& {[\mathrm{C}](t)=\left(1-\frac{k_{2} e^{k_{1} t}-e^{k_{2} t}}{k_{2}-k_{1}}\right)}
\end{aligned}
$$

Eq. (1), an integrated first-order decay equation, was used to determine the rate of loss per hour $\left(\mathrm{h}^{-1}\right)$ of parent molecules $(A)$ in the exposure media and test system for primary hepatocytes and 
PLHC-1 cells, where $\left[A_{0}\right]$ refers to the initial dosed concentration at time zero and $k$ refers to the first-order rate loss for time $t$. Eq. (2) is the integrated form of a first-order formation and decay function illustrating the uptake $(\mu \mathrm{mol} / \mathrm{g} / \mathrm{h})$ of parent molecules into cells (step A to $\mathrm{B}$ ) and loss $\left(\mathrm{h}^{-1}\right)$ through time due to biotransformation (step B to C). For this equation to be valid, it needs to be established that biotransformation was indeed measured. Eq. (3) describes the formation of total metabolites (C) in both media and cell fractions $(1 / \mathrm{h})$. All three equations together allow a mass balance of radiolabel in the microtiter plate test system to be determined.

\subsection{Extrapolation to bioconcentration in fish}

Intrinsic clearance rates $\left(V_{\max } / K_{m}\right)$ from subcellular tests and parent loss (due to biotransformation) from hepatocytes were used as inputs to an in vitro to in vivo extrapolation model for bioconcentration developed by Cowan-Ellsberry et al. (2008). Briefly, this model takes in vitro loss rates and scales them to in vivo liver loss rates and then, by using information on the amount of blood flowing through the liver and the effect of chemical binding to proteins and lipid in blood relative to that in the test system, the in vivo hepatic clearance is estimated. The final step is to estimate the whole body biotransformation rate constant, $k_{M E T}$, that takes into account how much of the chemical will be distributed from the blood to other tissues (i.e., volume of distribution). BCFs were determined by the mass-balance model described by Arnot and Gobas (2003, 2004). Default BCFs were calculated, assuming no metabolism $\left(k_{M E T}=0\right)$ for a $1 \mathrm{~kg}$ trout or carp with $10 \%$ lipid content exposed to the parent materials at 12 and $23^{\circ} \mathrm{C}$, respectively.

\subsection{Statistics}

Values were compared using one-way analysis of variance (ANOVA) and are expressed as means \pm SD. When significant $(p<0.05)$, differences were further tested using a Tukey multiple comparison test.

\section{Results}

\subsection{Cytotoxicity}

Cytotoxicity of C16EO8 was determined for both primary hepatocytes and PLHC-1 cells. PLHC- 1 cells were more sensitive than primary hepatocytes, as the EC50s were 7.9 and $29.2 \mu \mathrm{M}$, respectively (Table 1 ). Similarly, PLHC- 1 cells were more sensitive to C14EO2S than primary cells. The EC50 values for C14EO2S were 125.8 and $105.3 \mu \mathrm{M}$ for primary and PLHC-1 cells, respectively (Table 1). Based on the concentration response relationships, incubations for kinetics studies with C16EO8 were conducted at 2.5 and $5 \mu \mathrm{M}$ for PLHC-1 and primary cells, whereas for C14EO2S, both PLHC- 1 and primary cells were incubated at $40 \mu \mathrm{M}$.

\subsection{Subcellular characterization}

Esterase activity and biotransformation of 7-ethoxycoumarin (ECOD) were obtained for carp liver homogenates and microsomes as well as rainbow trout microsomes. Regarding esterase activity (expressed as $\mu \mathrm{mol} / \mathrm{h} / \mathrm{mg}$ protein), carp microsomal activity was significantly greater than carp homogenates (data in Dyer et al., 2008). ECOD activities of microsomes from carp and trout were greater than carp homogenates (data in Dyer et al., 2008). The ECOD activity in trout was similar to that reported by Banka et al. (1997).

The effect of the surfactants on ECOD activity in carp liver homogenates and microsomes was investigated. Compared to controls, no significant differences in activities were observed in both subcellular fractions at $100 \mu \mathrm{M} \mathrm{C16EO} 8$ and C14EO2S.

\subsection{Cellular kinetics}

\subsection{1. $C 16 E 08$}

A mass balance of radiolabeled C16EO8 in primary hepatocytes and PLHC- 1 cells was determined. The total average recovery for the primary cell system was $94.4 \pm 6.9 \%$ and $93.4 \pm 2.8 \%$ for PLHC-1 cells, as determined by LSC. The average extraction efficiency of media samples for both cell types via TLC was $108.4 \pm 32.5 \%$. For both cell types, the average extraction efficiency was $102.4 \pm 31.7 \%$.

A majority of radiolabeled parent C16EO8 was found in the overlying media for both cell systems. Mean media fractions in the primary cell experiments throughout all time points ranged from $89.3 \%$ to $65.7 \%$, decreasing throughout the $72 \mathrm{~h}$ study. The remaining fraction was detected in the cellular fraction where means ranged from $2.1 \%$ to $23.8 \%$, increasing throughout the study period. Media blanks (no cells) ranged from $92.1 \%$ to $88.4 \%$ and well rinses ranged from $0.6 \%$ to $1.8 \%$, but with no temporal pattern. Similar results were found for the PLHC- 1 cells where media fractions ranged from $94.1 \%$ to $78.6 \%$, decreasing through time while the cellular fractions ranged from $1.6 \%$ to $6.9 \%$, increasing through time. Media blanks ranged from $84.1 \%$ to $93.6 \%$ and well rinses from $0.9 \%$ to $1.3 \%$, both with no temporal change.

Thin layer chromatograms provided data for the proportion of parent C16EO8 in overlying media, cells and metabolites found in both cell and media fractions. Parent C16EO8 was rapidly taken up by the primary hepatocyte cell fraction and biotransformed to both polar and non-polar metabolites resulting in a loss over time (Fig. 1). The proportion of metabolites increased throughout the exposure period in both cellular and media fractions. The uptake and loss (attributable to biotransformation) of the parent material in the hepatocytes was modeled using a first-order formation and decay model. The loss of parent material from the overlying media was modeled using a first-order decay model. Biotransformation products in both media and cellular fractions were modeled using a first-order formation model. Coefficients of determination $\left(R^{2}\right)$ for all models were between 0.95 and 0.98 . The overall good fit for each of the first-order models indicated that the loss of the parent material from the media was due to the uptake of the parent into the cell and then biotransformed. The resulting metabolites were found in both media and cellular fractions, evidence of metabolite efflux from the cellular fraction as well as partitioning within the cell. Considering these findings and assuming a completely mixed model, the parent loss rate from the entire test sys-

Table 1

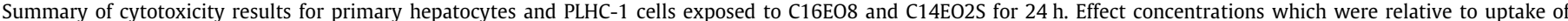

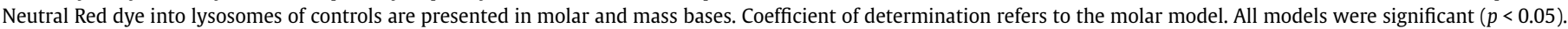

\begin{tabular}{|c|c|c|c|c|c|}
\hline Cell type & Test compound & $\operatorname{EC50}(\mu \mathrm{M})$ & 95\% confidence limits & $\mathrm{EC} 50(\mathrm{mg} / \mathrm{L})$ & $R^{2}$ \\
\hline Primary & C16EO8 & 29.2 & $26.4-31.9$ & 49.1 & 0.91 \\
\hline PLHC-1 & C16EO8 & 7.9 & 7.4-8.5 & 13.3 & 0.97 \\
\hline Primary & C14EO2S & 125.8 & $119.7-132.3$ & 311.4 & 0.86 \\
\hline PLHC-1 & C14EO2S & 105.3 & $103.3-107.6$ & 260.6 & 0.98 \\
\hline
\end{tabular}



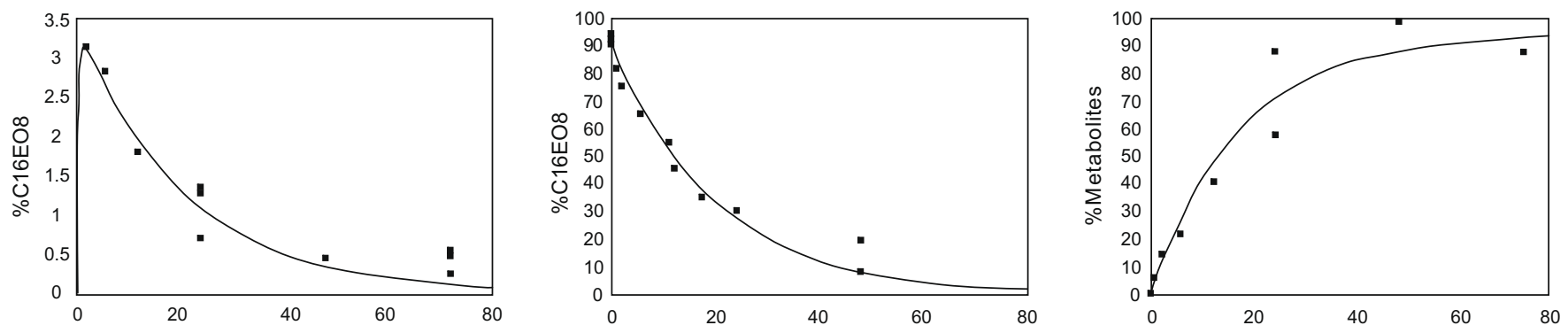

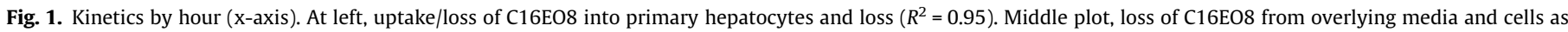

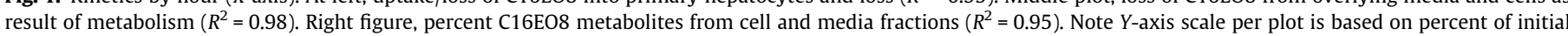
parent molecule radioactivity.

tem (media and cell fractions) was determined to be $0.069 \mathrm{nmol} /$ cell/h. Considering the test volume and concentration of test material, the in vitro intrinsic clearance rate was $2.78 \mathrm{E}-06 \mathrm{~mL} / \mathrm{cell} / \mathrm{h}$ (Table 2). This value was used in the Cowan-Ellsberry et al. (2008) extrapolation model to predict the in vivo metabolism rate $\left(k_{M E T}\right)$ and bioconcentration factor. The predicted $k_{M E T}$ and BCF were $0.768 \mathrm{~d}^{-1}$ and 123.4 , respectively. Using the Cowan-Ellsberry model, assuming no in vivo biotransformation, the default BCF was 2556 for carp.

PLHC-1 cells illustrated uptake of the parent C16EO8 and generation of polar metabolites in cellular and media fractions. However, the proportion of radiolabeled material converted to metabolites was much less, compared to primary cells, suggesting that efflux pumps may play a greater role in parent loss from cells compared to primary hepatocytes (Fig. 2). Normalized on a per protein basis, the rate of uptake C16EO8 in PLHC-1 was similar to that of primary cells, however, the rate of loss was nearly an order of magnitude slower (Table 2).

\subsection{2. $C 14 E O 2 S$}

For C14EO2S, the total average recovery for primary cell system was $93.6 \pm 3.4 \%$ as determined by LSC. The average extraction efficiency of all media samples via TLC was $98.1 \%$ Similar results were found with PLHC- 1 cells where the total recovery and extraction efficiencies for media and cells were $96.5 \pm 1.7 \%, 98.1 \pm 6.1 \%$ and $114.6 \pm 6.8 \%$, respectively.

A majority of radiolabeled parent C14EO2S was found in the overlying media for both cell systems. Mean media fractions in the primary cell experiments throughout all time points ranged from $86.1 \%$ to $75.9 \%$, decreasing throughout the 72 h study. The remaining fraction was detected in the cellular fraction where means ranged from $1.6 \%$ to $17.2 \%$, increasing throughout the study period. Media blanks (no cells) ranged from $97.8 \%$ to $85.8 \%$ and well rinses ranged from $0.8 \%$ to $1.6 \%$, but with no temporal pattern. Similar results were observed for PLHC-1 studies where mean media fractions ranged form $91.5 \%$ to $85.8 \%$, decreasing throughout the $72 \mathrm{~h}$ study. Remaining cellular fractions ranged from $3.8 \%$ to $8.5 \%$, increasing throughout the study period. Media blanks (no cells) ranged from $94.0 \%$ to $121 \%$ and well rinses ranged from $0.8 \%$ to $1.6 \%$, but with no temporal pattern.

TLCs provided data for the proportion of parent C14EO2S in overlying media, cells and metabolites generated in both cell and media fractions. Parent C14EO2S was rapidly taken up by the primary hepatocyte cell fraction and biotransformed to both polar and non-polar metabolites resulting in a loss over time (Fig. 3). The proportion of metabolites increased throughout the exposure period in both cellular and media fractions. The uptake and loss (attributable to biotransformation) of the parent material in the hepatocytes was modeled using a first-order formation and decay model. The loss of parent material from the overlying media was modeled using a first-order decay model. Biotransformation products in both media and cellular fractions were modeled using a first-order formation model. Coefficients of determination $\left(R^{2}\right)$ for all models were between 0.87 and 0.98 . The overall good fit for each of the first-order models indicated that the loss of the parent material from the media was due to the uptake of the parent into the cell and then biotransformed. The resulting metabolites were found in both media and cellular fractions, evidence of metabolite efflux from the cellular fraction as well as partitioning within the cell. Considering these findings and assuming a completely mixed model, the parent loss rate from the entire test system (media and cell fractions) was determined to be $0.0079 \mathrm{nmol} / \mathrm{cell} / \mathrm{h}$. Considering the test volume and concentration of test material, the in vitro intrinsic clearance rate was $3.95 \mathrm{E}-08 \mathrm{~mL} /$ cell/h (Table 2 ). This value was used in the Cowan-Ellsberry et al. (2008) extrapolation model to predict the in vivo metabolism rate $\left(k_{M E T}\right)$ and bioconcentration factor of $0.157 \mathrm{~d}^{-1}$ and 10.3 , respectively. Assuming no in vivo biotransformation, the default BCF was 13.2 for carp. The kinetics of loss of C14EO2S from media, uptake into PLHC-1 cells and generation of metabolites did not follow first order-rate kinetics.

\subsection{Subcellular kinetics}

Biotransformation activity of C16EO8 over a $2 \mathrm{~h}$ period was investigated in carp microsomes and homogenates as well as in

Table 2

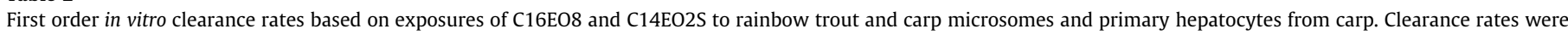

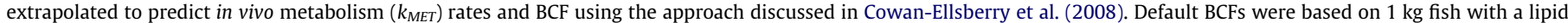
content of 0.1 , a $k_{M E T}$ of zero with trout and carp being exposed to 12 and $23^{\circ} \mathrm{C}$, respectively.

\begin{tabular}{|c|c|c|c|c|c|c|}
\hline \multirow[b]{2}{*}{ Chemical } & \multirow[b]{2}{*}{ Species } & \multicolumn{2}{|l|}{ In vitro clearance rates } & \multicolumn{3}{|c|}{ Predicted fish $k_{M E T}$} \\
\hline & & Subcellular (mL/h/g protein) & Cellular (mL/cell/h) & $\left(d^{-1}\right)$ & Predicted BCF & Default BCF \\
\hline C16EO8 & Trout & 229.3 & & 0.031 & 1516 & 2881 \\
\hline C16EO8 & Carp & 30.5 & & 0.009 & 2073 & 2556 \\
\hline C14EO2S & Trout & 38.7 & & 0.024 & 13.1 & 13.2 \\
\hline C14EO2S & Carp & 28.6 & & 0.035 & 13.1 & 13.2 \\
\hline C16EO8 & Carp & & $2.78 \mathrm{E}-06$ & 0.768 & 123.4 & 2556 \\
\hline C14EO2S & Carp & & $3.95 \mathrm{E}-08$ & 0.157 & 10.3 & 13.2 \\
\hline
\end{tabular}



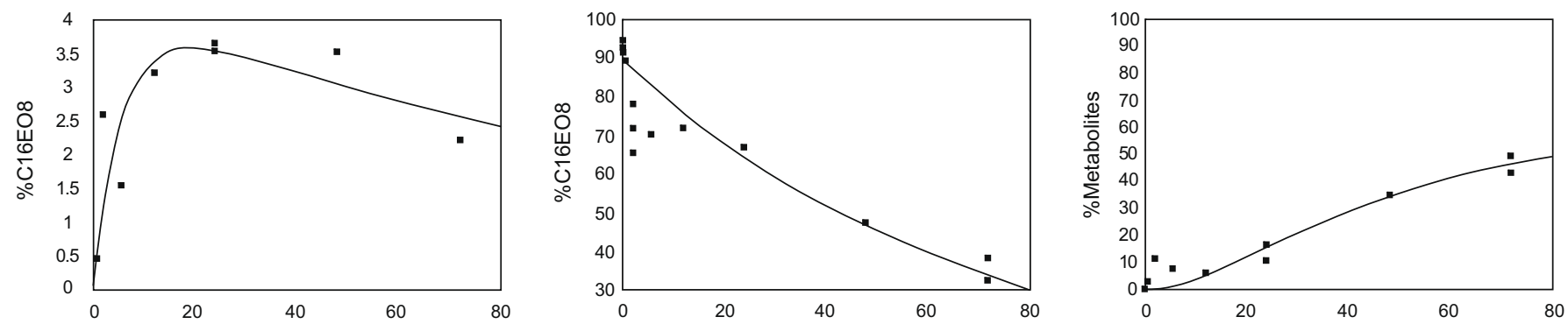

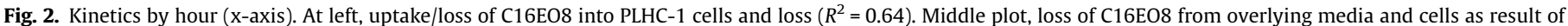
metabolism $\left(R^{2}=0.91\right)$. Right figure, percent C16EO8 metabolites from cell and media fractions $\left(R^{2}=0.92\right)$. Note $Y$-axis scale per plot.
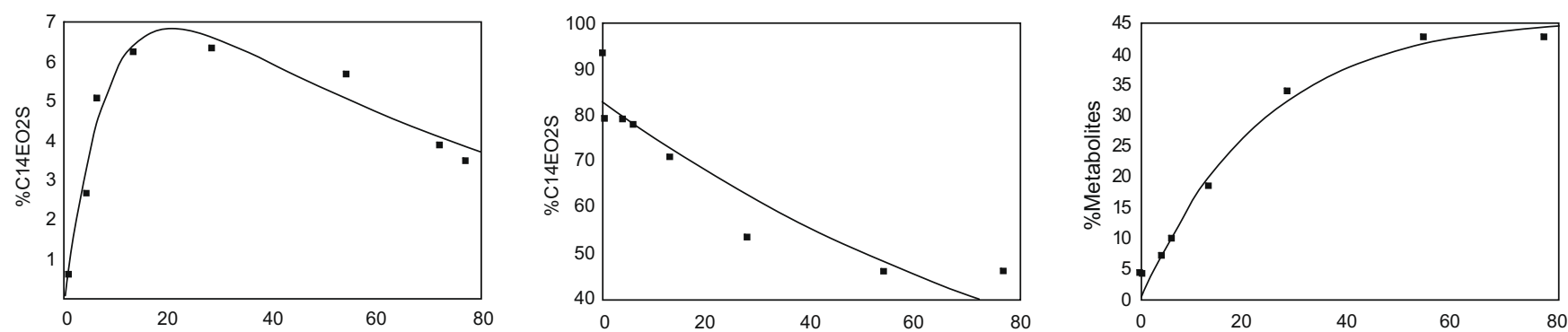

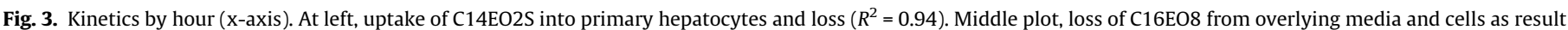
of metabolism $\left(R^{2}=0.87\right)$. Right figure, percent C16EO8 metabolites from cell and media fractions $\left(R^{2}=0.98\right)$. Note $Y$-axis per plot.

rainbow trout microsomes. Four C16EO8 concentrations $(10,50$, 100 and $200 \mu \mathrm{M}$ ) were incubated with carp liver subcellular fractions. In microsomes as in homogenates, two metabolites were produced and migrated at Rf 0.80 and 0.87 . In homogenates, at the $200 \mu \mathrm{M}$ concentration, metabolite production was too low to be measured. The production of metabolites followed MichaelisMenten kinetics increasing with the concentration of C16EO8 and reaching saturation at $100 \mu \mathrm{M}$ in microsomal fractions (Fig. 4A). However, microsomal biotransformation of C16EO8 in trout was greater than found in carp (Fig. 4B). Michaelis-Menten parameters $\left(V_{\max }\right.$ and $\left.K_{m}\right)$ for the production of metabolites were calculated according to the nonlinear regression equation from microsomal incubations. Mean $V_{\max }$, (pmol/min/mg prot), and $K_{m}$ $(\mu \mathrm{M})$, parameters for carp microsomes incubated with C16EO8 were 68.94 and 135.68 , respectively, whereas they were 289.97 and 75.87 from trout microsomal incubations.

Biotransformation of $\mathrm{C} 14 \mathrm{EO} 2 \mathrm{~S}$ was also greater in carp microsomes compared to homogenates (Fig. 5A). However, the rate of microsomal biotransformation from carp was very similar to that of rainbow trout (Fig. 5B). Mean $V_{\max }$ and $K_{m}$ parameters from carp microsomes incubated with C14EO2S were 76.86 and 161.46, whereas the same parameters observed via incubations with trout microsomes were 47.87 and 74.17. The ratio of the $V_{\max }$ and $K_{m}$ provided the in vitro intrinsic clearance rates presented in Table 2.

\subsection{Extrapolations}

Predicted in vivo metabolism rates $\left(k_{M E T}\right)$ ranged from 0.009 to $0.035\left(\mathrm{~d}^{-1}\right)$ for both surfactants and fish species based on microsomal in vitro clearance rates (Table 2). However, much faster $k_{M E T}$ values were estimated based on carp hepatocyte tests, ranging from $0.768\left(\mathrm{~d}^{-1}\right)$ for C16EO8 to $0.157\left(\mathrm{~d}^{-1}\right)$ for C14EO2S. In all cases, the predicted BCFs based on the in vitro to in vivo extrapolation methods by Cowan-Ellsberry et al. (2008) were less than the default BCF values (assuming no biotransformation) based on a $1 \mathrm{~kg}$ fish with a lipid content of $10 \%$ with trout and carp being exposed to 12 and $23^{\circ} \mathrm{C}$, respectively. The greatest difference from
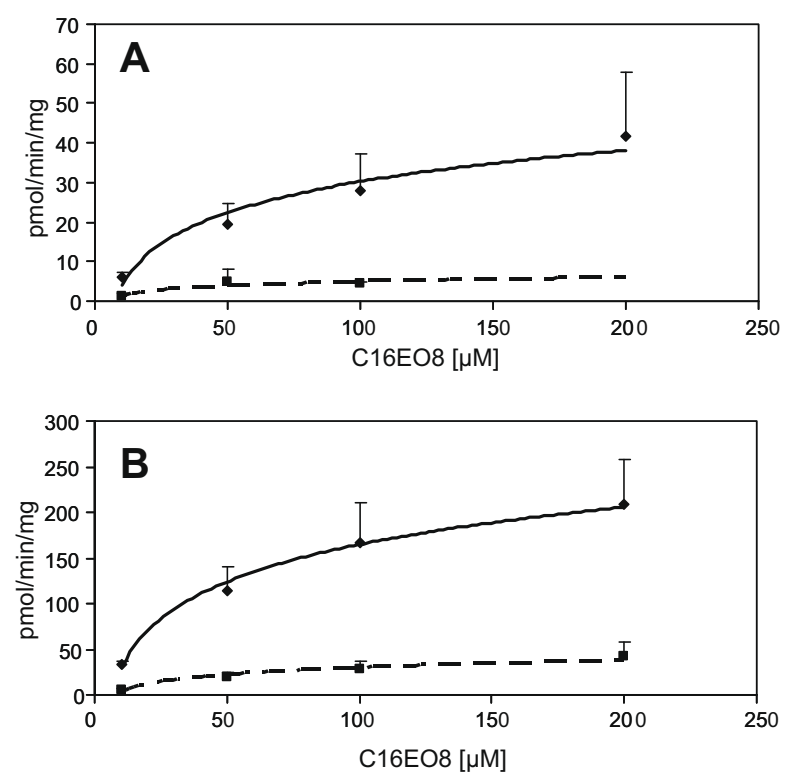

Fig. 4. (A). Michaelis-Menten kinetics for the biotransformation of C16EO8 in carp microsomes (diamonds, solid line) and homogenates (squares, dashed line). (B). Comparison of kinetics for the biotransformation of C16EO8 in microsomes from rainbow trout (diamonds, solid line) and carp (squares, dashed line). Values are means \pm SD from three pools of fish.

default values were found for hepatocyte tests. For example, the default $\mathrm{BCF}$ value for $\mathrm{C} 16 \mathrm{EO} 8$ at $23^{\circ} \mathrm{C}$ was 2556 whereas when incorporating the hepatocyte-derived in vitro clearance rate, the predicted BCF was 123.4.

\section{Discussion}

For both primary hepatocytes and PLHC-1 cells, C16EO8 was found to be more cytotoxic than C14EO2S. Of the two cell types, 

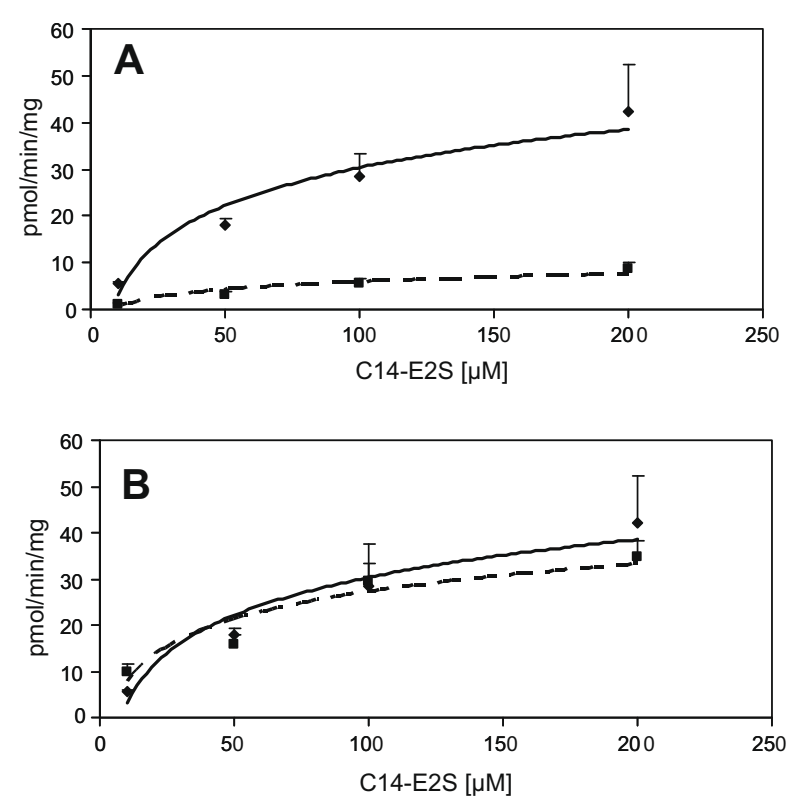

Fig. 5. (A). Michaelis-Menten kinetics for the biotransformation of C14EO2S in carp microsomes (diamonds, solid line) and homogenates (squares, dashed line). (B). Comparison of kinetics for the biotransformation of C14EO2S in microsomes from rainbow trout (diamonds, solid line) and carp (squares, dashed line). Values are means \pm SD from three pools of fish.

PLHC-1 cells were more sensitive to both surfactants. Median effect concentrations reported here were based on nominal concentrations, a typical practice in cytotoxicological studies. Our past studies with surfactants have shown that nominal concentrations are useful to gain a relative understanding of toxicity, whereas determining cell burdens associated with toxicity provides a direct measure of cytotoxicity (Bernhard and Dyer, 2005). In this case we investigated cytotoxicity to determine the maximum test chemical concentration for which biotransformation could be assessed without causing toxicity.

Both PLHC-1 and primary hepatocytes from the carp showed uptake and loss of C16EO8 due to metabolism. Via a first-order formation and decay model, rates of uptake into fish cells and loss of parent compounds from cells were determined (Figs. 1 and 2). First-order uptake and loss due to metabolism was also found in primary hepatocytes exposed to C14EO2S (Fig. 3) however, PLHC1 cells exposed to $\mathrm{C} 14 \mathrm{EO} 2 \mathrm{~S}$ did not conform to the first-order rate model. For both test materials the fraction of total radioactivity measured as metabolites in cells and overlying media was greater with the primary hepatocytes than PLHC-1 cells. Thin layer chromatograms for both media and cellular fractions illustrated that the number of potential metabolites were also greatest in primary cells (not shown). It should be noted that our observations of the majority of the parent surfactants partitioning within the overlying media fraction instead of the cells and plastic microtiter plate walls is due to their amphiphilic property (i.e., polar and non-polar ends). It is possible that the microtiter plated-based method may prove difficult with more highly hydrophobic materials (e.g., non-polar with $\log K o w>4.5$ ), as these materials will have a propensity to strongly bind to plastic walls.

All the tested fractions (microsomes and liver homogenates) were suitable for measuring ECOD and esterase activities and the comparisons between microsomes and homogenates using the surfactants as substrates indicated similar qualitative results (data in Dyer et al., 2008). Nevertheless, the fastest observed metabolic rates were with microsomes, calculated on a protein basis, therefore microsomes would be preferred for assessing the potential for in vivo biotransformation. The present study showed that C16EO8 was metabolized at a greater extent by trout hepatic microsomes than by those from carp (Table 2 and Fig. 4), whereas C14EO2S was biotransformed similarly in both species (Fig. 5). The comparison of our results with the data reported previously for other surfactants (Dyer et al., 2008) indicates that in carp, C16EO8 and C14EO2S are biotransformed at a lower extent than C12LAS and C13EO8. In trout, the biotransformation rate for C16EO8 was slightly greater than the values measured for C12LAS and C13EO8, whereas the biotransformation of C14EO2S was limited as compared with these compounds (Dyer et al., 2008).

The common pathway for the biotransformation of surfactants is either an enzymatic cleavage of the non-polar and polar surfactant moieties (forming a fatty alcohol/acid and a hydrophilic product) or a terminal oxidation and subsequent stepwise degradation of the alkyl chain (leaving again a more hydrophilic product). The metabolism of the surfactant alkyl chain through a combination of $\omega$ - and $\beta$-oxidations, with subsequent excretion of a short chain derivative has been demonstrated for several fish species (Newsome et al, 1995; Thibaut et al., 1998; Van Egmond et al., 1999; Tolls and sijm, 1999; Arukwe et al., 2000; Cravedi et al., 2001). The enzyme systems involved in these metabolic steps ( $\omega$ - and $\omega-1$, and $\beta$-oxidations) are mainly present in the liver and are located in microsomes and mitochondria (Thibaut et al., 2002).

In vitro test system clearance rates of parent chemical substrates from both cellular and subcellular test systems were determined and used as inputs into the extrapolation model by CowanEllsberry et al. (2008). This model incorporates exposure temperature and physiological characteristics of fish, including hepatic blood flow, to estimate the whole body biotransformation rate $\left(k_{M E T}\right)$. The $k_{M E T}$ is one of the most important modifying factors in the bioconcentration model by Arnot and Gobas (2003, 2004). Hence, the extrapolation model provides a link between in vitro metabolism rate to in vivo metabolism rate and then bioconcentration. This approach has also been discussed by Han et al., (2007) and Nichols et al. $(2006,2007)$. Based on a log Kow of 4.5 for C16EO8, the default BCFs, assuming no metabolism, were 2881 and 2556 for rainbow trout and carp exposed at 12 and $23^{\circ} \mathrm{C}$, respectively. For C14EO2S, the default BCFs for trout and carp were the same, 13.2, due to the relatively low log Kow value of 2.1. Inclusion of in vitro clearance in the extrapolation model yielded predicted BCFs for C16EO8 of 1516 and 2073 via microsomal tests with trout and carp, respectively. A BCF of 13.1 was predicted based on carp and trout microsomal tests with C14EO2S. Lower predicted BCFs resulted from tests with primary hepatocytes from carp, where the BCFs of 123.4 and 10.3 were estimated for C16EO8 and C14EO2S, respectively. The relative difference between hepatocytes and microsomes have also been observed by Han et al. (2009), where intrinsic in vitro rates and extrapolated BCFs were compared to measured BCFs for a wide array of compounds, such as molinate, Michler's ketone, 4-nonylphenol, 2,4-di-tert-butylphenol and benzo(a)pyrene. In that study, rates from hepatocytes always exceeded that of subcellular fractions, therefore also leading to lower BCFs.

The predicted BCFs for C16EO8 from microsomal and cellular studies bounded the only measured in vivo BCF value, 387.5 for fathead minnow (Tolls et al., 2000). The USEPA program BCFWIN predicted an in vivo value of 62 . No published in vivo BCF data are available for C14EO2S. However, BCFWIN predicted a BCF value of 71 for this material, which was similar to data from an unpublished study by P\&G where fish were exposed to a commercial alcohol ethoxylate sulfate containing C14EO2S in an experimental stream study.

It has been proposed that there is a need for in vitro systems for investigating biotransformation, toxicity, mechanisms and kinetics of potentially bioaccummulative chemicals (Blaauboer et al., 1994; 
DeWolf et al., 2006; Nichols et al., 2006; Nichols et al., 2007; Han et al., 2007; Cowan-Ellsberry et al., 2008). The validity of these systems needs to be urgently evaluated as there are increasing regulatory needs to assess biotransformation and toxicity. For example, under the REACh (Registration, Evaluation and Authorization of Chemicals) regulatory framework for chemicals in the European Union, a chemical is considered 'bioaccumulative' if the BCF is greater than 2000, and 'very bioaccumulative' if the BCF if greater than 5000 (DGEE, 2003). Based on log Kow alone, C16EO8 could have been interpreted to have a default BCF exceeding the 'bioaccumulative' criterion, contrary to results from rainbow trout microsomes and carp hepatocytes which clearly show that predicted BCFs that incorporate metabolism resulted in a non-bioaccumulative classification status. Within REACh, in vitro systems can potentially play a very important role in future BCF assessments by providing rapid screening for chemical biotransformation while reducing animal usage, time and cost.

Between our data (this study and Dyer et al., 2008) and that of (Han et al., 2007, 2009), it is becoming quite clear that subcellularbased tests provide more conservative (slower) in vitro clearance rates than those from hepatocyte-based tests. While these findings fit well within a tiered structure proceeding from subcellular to cellular to modified OECD 305 studies and culminating in official OECD 305 BCF studies, it does beg the question why even conduct subcellular tests and/or how can hepatocyte studies become more accessible? At present, there is a commercial supply for rainbow trout S9, hence any laboratory may be able conduct preliminary BCF assessments that include S9-based metabolic corrections. Needed, however, are commercial supplies of cryopreserved fish hepatocytes that will enable any laboratory to conduct BCF assessments, but by including more realistic hepatic clearance rates. For future acceptance of in vitro methods, it is imperative that development of such cryopreserved cells be created and evaluated, with the hope the metabolically-corrected BCFs can become a routine exercise for bioconcentration assessments.

\section{Acknowledgments}

The authors thank ERASM for funding this study and to members of the ERASM Biotransformation Task Force and Sylvia Gimeno for their thoughtful comments and reviews over the period of this Project. We also wish to thank Raymond Gazel for excellent technical support, Tom Federle for suggesting the first-order formation and decay model for derivation of cellular BCFs and to Drew McAvoy for reviewing our kinetics modeling and calculus approach. Additionally, the synthesis lab at Procter and Gamble is acknowledged for providing various test chemicals.

\section{References}

Arnot, J.A., Gobas, F.A.P.C., 2003. A generic QSAR for assessing the bioaccumulation potential of organic chemicals in aquatic food webs. QSAR Comb. Sci. 22 (3), 337-345.

Arnot, J.A., Gobas, F.A.P.C., 2004. A food web bioaccumulation model for organic chemicals in aquatic ecosystems. Environ. Toxicol. Chem. 23, 2343-2355.

Arukwe, A., Goksoyr, A., Thibaut, R., Cravedi, J.P., 2000. Metabolism and organ distribution of nonylphenol in Atlantic salmon (Salmo salar). Mar. Environ. Res. $50,141-145$

Banka, L., Deer, K.A., Nemcsok, J., Abraham, M., 1997. In vivo and in vitro effects of deltamethrin on cytochrome P450 monooxygenase activity in carp (Cyprinus carpio L.) liver. J. Environ. Sci. Health B. 32, 789-802.

Bernhard, M.J., Dyer, S.D., 2005. Fish critical cellular residues for surfactants and surfactant mixture. Environ. Toxicol. Chem. 24, 1738-1744.

Blaauboer, B.J, Boobis, A.R., Castell, J.V., Coecke, S., Groothuis, G.M.M., Guillouzo, A. Hall, T.J., Hawksworth, G.M., Lorenzon, G., Miltenburger, H.G., Rogiers, V., Skett, P., Villa, P., Wiebel, F.J., 1994. The practical applicability of hepatocyte cultures in routine testing, the report and recommendations of ECVAM Workshop 1. ATLA 22, 231-241.

Connell, D.W., 1993. The octanol-water partition coefficient. In: Calow, P. (Ed.), Handbook of Ecotoxicology, vol. 2. Blackwell Scientific Publication, London, pp. 311-320.
Cowan-Ellsberry, C.E., Dyer, S.D., Erhardt, S., Bernhard, M.J., Roe, A., Dowty, M.E., Weisbrod, A.V., 2008. Approach for extrapolating in vitro metabolism data to refine bioconcentration factor estimates. Chemosphere 10, 1804-1817.

Cravedi, J-P., 2002. Role of biotransformation in the fate and toxicity of chemicals: consequences for the assessment of residues in fish. Rev. Med. Vet. 153, 416424.

Cravedi, J-P., Boudry, G., Baradat, M., Rao, D., Debrauwer, L., 2001. Metabolic fate of 2,4-dichloroaniline, prochloraz and nonylphenol diethoxylate in rainbow trout: a comparative in vivo/in vitro approach. Aquat. Toxicol. 53, 159-172.

DeWolf, W., Comber, M., Douben, P., Gimeno, S., Holt, M., Leonard, M., Lilicrap, A., Sijm, D., van Egmond, R., Weisbrod, A., White, G., 2006. Animal use replacement, reduction and refinement: development of an integrated testing strategy for bioconcentration of chemicals in fish. Integrat. Environ. Assess. Manage. 3, 317.

DGEE, 2003. Directorates General Enterprise and Environment. The New EU Chemicals Legislation REACH. DG Enterprise, Brussels, Belgium. (<http:// www.europa.eu.int/comm/enterprise/reach/index_en.htm>).

Drotman, R.B., 1980. The absorption, distribution and excretion of alkylpolyethoxylates by rats and humans. Toxicol. Appl. Pharmacol. 52, 38-44.

Dyer, S.D., Bernhard, M.J., Cowan-Ellsberry, C., Perdu-Durand, E., Demmerle, E., Cravedi, J.P., 2008. In vitro biotransformation of surfactants in fish. Part 1: linear alkylbenzene sulfonate (C12-LAS) and alcohol ethoxylate (C13EO8). Chemosphere 72, 850-862.

Government of Canada, 1999. Canadian Environmental Protection Act. Canada Gazette Part III. 22.

Han, X., Nabb, D.L., Mingoia, R.T., Yang, C.-H., 2007. Determination of xenobiotic intrinsic clearance in freshly isolated hepatocytes from rainbow trout (Oncorhynchus mykiss) and rat and its application to bioaccumulation. Environ. Sci. Technol. 41, 3269-3276.

Han, X., Nabb, D.L., Yang, C.-H., Snajdr, S.I., Mingoia, R.T., 2009. Liver microsomes and S9 from rainbow trout (Oncorhynchus mykiss): comparison of basal-level enzyme activities with rat and determination of xenobiotic intrinsic clearance support of bioaccumulation assessment. Environ. Toxicol. Chem. 28, 481488.

Matthijs, E., Debaere, G., Itrich, N., Masscheleyn, P., Rottiers, A., Stalmans, M., Federle, T., 1995. The fate of detergent surfactants in sewer systems. Water Sci. Technol. 31, 321-328.

Meylan, W.M., Howard, P.H., Boethling, R.S., Aronson, D., Printup, H., Gouchie, S., 1999. Improved method for estimating bioconcentration/bioaccumulation factor from octanol/water partition coefficient. Environ. Tox. Chem. 18, 664672

Neff, J.M., 2002. Bioaccumulation in Marine Organisms. Elsevier, Amsterdam.

Newsome, C.S., Howes, D., Marshall, S.J., Van Egmond, R.A., 1995. Fate of some anionic and alcohol ethoxylate surfactants in Carassius auratus. Tenside Surfact. Det. 32, 498-503.

Nichols, J.W., Schultz, I.R., Fitzsimmons, P.N., 2006. In vitro-in vivo extrapolation of quantitative hepatic biotransformation data for fish. I. A review of methods, and strategies for incorporating intrinsic clearance estimates into chemical kinetic models. Aquat. Toxicol. 78, 74-90.

Nichols, J., Erhardt, S., Dyer, S., James, M., Moore, M., Plotzke, K., Segner, H., Schultz, I., Thomas, K., Vasiluk, L., Weisbrod, A., 2007. Use of in vitro absorption, distribution, metabolism, and excretion (ADME) data in bioaccumulation assessments for fish. Human Ecol. Risk Assess. 13, 1164-1191.

OECD, 1996. OECD Guidelines for Testing of Chemicals. 305. Bioconcentration: Flow-through Fish Test, last updated 14th June 1996. Organisation for Economic Co-operation and Development, Paris, France.

Perdu-Durand, E.F., Cravedi, J-P., 1989. Characterization of xenobiotic metabolizing enzymes in sturgeon (Acipenser baeri). Comp. Biochem. Physiol. Part B: Biochem. Mol. Biol. 93, 921-928.

Schultz, M.E., Schultz, R.J., 1985. Transplantable chemically-induced liver tumors in the viviparous fish Poeciliopsis. Exp. Mol. Pathol. 1985 42, 320-330.

Thibaut, R., Debrauwer, L., Rao, D., Cravedi, J.P., 1998. Disposition and metabolism of [3H]-4-n-nonylphenol in rainbow trout. Mar. Environ. Res. 46, 521-524.

Thibaut, R., Debrauwer, L., Perdu, E., Goksoyr, A., Cravedi, J.P., Arukwe, A., 2002. Regio-specific hydroxylation of nonylphenol and the involvement of CYP2Kand CYP2M-like iso-enzymes in Atlantic salmon (Salmo salar). Aquat. Toxicol. $56,177-190$.

Tolls, J., 1998. Bioconcentration of Surfactants. Ph.D. Dissertation, University of Utrecht, Utrecht, The Netherlands.

Tolls, J., Sijm, D.T.H.M., 1995. A preliminary evaluation of the relationship between bioconcentration and hydrophobicity for surfactants. Environ. Toxicol. Chem. $14,1675-1685$

Tolls, J., Sijm, D.T.H.M., 1999. Bioconcentration and biotransformation of the nonionic surfactant octaethylene glycol monotridecyl ether ${ }^{14} \mathrm{C}-\mathrm{C} 13 \mathrm{EO} 8$. Environ. Toxicol. Chem. 18, 2689-2695.

Tolls, J., Kloepper-Sams, P., Sijm, D.T.H.M., 1994. Surfactant bioconcentration: a critical review. Chemosphere 29, 693-717.

Tolls, J., Haller, M., de Graaf, I., Thijssen, M.A.T.C., Sijm, D.T.H.M., 1997. Bioconcentration of LAS: experimental determination and extrapolation to environmental mixtures. Environ. Sci. Technol. 31, 3426-3431.

Tolls, J., Haller, M., Labee, E., Verweij, M., Sijm, D.T.H.M., 2000. Experimental determination of bioconcentration of the nonionic surfactant alcohol ethoxylate. Environ. Toxicol. Chem. 19, 646-653.

Van Egmond, R., Hambling, S., Marshall, S., 1999. Bioconcentration, biotransformation, and chronic toxicity of sodium laurate to zebrafish (Danio rerio). Environ. Toxicol. Chem. 18, 466-473. 
Veith, G.D., De Foe, D.L., Bergstedt, B.V., 1979. Measuring and estimating the bioconcentration of chemicals in fish. J. Fish. Res. Bd. Can. 36, 10401048.
Zalko, D., Perdu-Durand, E., Debrauwer, L., Bec-Ferté, M.P., Tulliez, J., 1998 Comparative metabolism of clenbuterol by rat and bovine liver microsomes and slices. Drug Metab. Dispos. 26, 28-35. 